\title{
ФОРМИРОВАНИЕ МЕТОДИКИ ОЦЕНКИ РИСКА БАНКРОТСТВА ПРЕДПРИЯТИЙ МИНЕРАЛЬНО-СЫРЬЕВОГО СЕКТОРА
}

\author{
(c) 2018 Лютягин Дмитрий Владимирович \\ кандидат экономических наук, доцент, кафедра экономики минерально-сырьевого комплекса \\ Российский государственный геологоразведочный университет им. Серго Орджоникидзе \\ (МГРИ-РГГРУ) \\ 117997, Москва, ул. Миклухо-Маклая, д. 23 \\ E-mail:1-d-v@list.ru \\ (c) 2018 Морева Екатерина Николаевна \\ магистрант, кафедра экономики минерально-сырьевого комплекса \\ Российский государственный геологоразведочный университет им. Серго Орджоникидзе \\ (МГРИ-РГГРУ) \\ 117997, Москва, ул. Миклухо-Маклая, д. 23 \\ E-mail: morevakatya08061994@mail.ru
}

\begin{abstract}
Минерально-сырьевая отрасль является одним из ключевых секторов экономики России, в связи с чем оценка риска банкротства горнодобывающих предприятий имеет приоритетное значение при разработке стратегии развития страны в целом. В исследовании, в соответствии с поставленной целью, предложена усовершенствованная методика оценки риска банкротства предприятий минерально-сырьевого комплекса. Особенностью разработанной методики является учет специфических факторов, присущих данной отрасли, а именно: уровень запасов, срок лицензии на разработку месторождений, геологический риск и др. показатели. Методика апробирована на золотодобывающем и угольном предприятиях, полученные результаты оценки которых свидетельствуют об адекватности предложенной методики.
\end{abstract}

Ключевые слова: банкротство, методика, минерально-сырьевой сектор, геологический риск, уровень запасов, лицензия.

Устойчивое развитие предприятий любой отрасли является залогом успешного функционирования экономики страны в целом. Однако, глобализационные процессы, являющиеся причиной распространения кризисных явлений по всей мировой экономике, а также наличие внутренних проблем в каждой стране оказывают негативное влияние на финансовую устойчивость субъектов хозяйствования. В этой связи, актуализируется вопрос определения вероятности банкротства предприятий, как инструмента управления эффективным экономическим развитием страны.

В мировой и отечественной практике наблюдается значительный интерес к методикам прогнозирования банкротства предприятий в последние десятилетия. Чаще всего в исследованиях упоминаются модели Альтмана, Спрингейта, Фулмера, Ж. Конана и М. Гольдбера, продемонстрировавших наиболее точные результаты оценки банкротства с течением времени. Отечественные исследователи также идут в ногу со временем, предлагая разнообразные вариации моделей прогнозирования риска банкротства субъекта хозяйствования. Учитывая современные реалии экономики, ряд авторов (Е.А. Федорова, С.Е. Довженко, Я.В. Тимофеева, М.Л. Яшина и Н.М. Нейфа, Е.С. Ткач, Ю.Д. Ханафиева и И.А. Чекушина и др.) стали делать акцент на разработке моделей риска банкротства, учитывающих отраслевые особенности предприятий, что однозначно является положительным фактором, повышающим точность предложенных моделей. Тем не менее, как показало ранее проведенное исследование, все еще отсутствуют методики оценивания риска банкротства предприятий минерально-сырьевого сектора, представляющих собою ключевые элементы в производственном цикле промышленных предприятий [7].

Учитывая изложенное выше, целью статьи является разработка методики определения риска банкротства для предприятий минерально-сырьевого комплекса. 
В настоящее время минерально-сырьевая отрасль представляет собой один из ключевых секторов экономики России, имеет важное социальное и экономическое значение, вносит основной вклад в бюджет страны, а также является основным ресурсом для перевода промышленного сектора на новый технологический уклад.

Являясь базисом существования человечества, природные ресурсы, демонстрируют постоянный рост их вовлечения в хозяйственный оборот экономики страны. Так, только за последние 60 лет в мировой экономике выработали и использовали больше минерального сырья, больше, чем за всю историю развития человеческой цивилизации [9].

Алгоритм построения методики включает в себя несколько этапов:

1) определение информационной базы для диагностики риска банкротства;

2) выбор системы показателей деятельности предприятия минерально-сырьевого комплекса;

3) сопоставление фактических и пороговых показателей и распределение их по зонам риска.

В основе предлагаемой методики оценки риска банкротства предприятий минерально-сырьевого комплекса лежит методика Правительства Российской Федерации «Правила проведения арбитражным управляющим финансового анализа», разработанная в соответствии с Федеральным законом «О несостоятельности (банкротстве)» (табл. 1).

В качестве базовых показателей из «Правил проведения арбитражным управляющим финансового анализа» нами выбраны [8]:

1. Показатели платежеспособности предприятия:

- коэффициент абсолютной ликвидности демонстрирует какую долю краткосрочных обязательств предприятие может моментально погасить за счет своих наиболее ликвидных оборотных активов;

- показатель текущей ликвидности показывает возможность предприятия погасить свои краткосрочные обязательства за счет своих оборотных активов;

- уровень платежеспособности по текущим обязательствам характеризует платежеспособность компании, сумму ее краткосрочных обязательств и сроки возможного погашения заемных средств за счет выручки.
2. Показатели, отражающие финансовую устойчивость предприятия

- коэффициент автономии демонстрирует какая часть активов предприятия обеспечивается собственными ресурсами.

- показатель обеспеченности собственными оборотными средствами отражает уровень обеспеченности собственными оборотными ресурсами (отношение разницы собственных средств и скорректированных внеоборотных активов к величине оборотных активов).

- коэффициент соотношения дебиторской задолженности к совокупным активам.

Показатели, характеризующие деловую активность предприятия:

- рентабельность активов отражает эффективность работы менеджмента и использования имущества компании.

- норма чистой прибыли демонстрирует степень прибыльности деятельности компании (измеряется в процентах и определяется как отношение чистой прибыли к выручке (нетто)).

Кроме коэффициентов, характеризующих финансовое положение предприятия, как отмечалось нами в [7], целесообразно учитывать показатели, отражающие специфику отрасли. Среди таких показателей выделим:

- уровень запасов - чем больше объемы и выше качество запасов на месторождениях, тем менее предприятие подвержено риску банкротства;

- срок действия лицензии - чем больше срок правообладания каким-либо месторождением, тем дольше предприятие сможет разрабатывать месторождение и таким образом обеспечивать себе эффективное функционирование;

- сезонность операций - в случае проведения сезонной деятельности, возможности предприятия получать прибыль регулярно снижаются, что повышает уровень возникновения риска банкротства;

- геологические риски - по уровню сложности добычи полезных ископаемых месторождения делятся на 4 группы, самой труднодоступной из которых является 4 группа. Данный вид риска также влияет на финансовые показатели предприятия, поскольку может вызвать дополнительные расходы на освоение труднодоступных месторождений;

- вид сырья - в настоящее время наиболее востребованными являются углеводороды, что позволяет присвоить им высшую оценку; 
Таблица 1. Показатели для оценки риска банкротства предприятий минерально-сырьевого комплекса

\begin{tabular}{|c|c|c|c|c|c|c|}
\hline \multirow{3}{*}{\begin{tabular}{l}
\multicolumn{1}{c}{ Показатель } \\
коэффициент абсолют- \\
ной ликвидности
\end{tabular}} & \multicolumn{6}{|c|}{ Баллы } \\
\hline & & & 2 & 3 & 4 & 5 \\
\hline & \multicolumn{2}{|c|}{$(0-0.1)$} & $(0.1-0.15)$ & $(0.15-0.22)$ & $(0.22-0.28)$ & Больше 0.28 , \\
\hline \multirow{2}{*}{$\begin{array}{l}\text { показатель текущей } \\
\text { ликвидности }\end{array}$} & \multicolumn{2}{|c|}{1} & 2 & 3 & 4 & 5 \\
\hline & \multicolumn{2}{|c|}{$(0-0.7)$} & $(0.7-1.4)$ & $(1.4-2.0)$ & $(2.0-2.35)$ & $\begin{array}{c}\text { (больше } \\
2.35)\end{array}$ \\
\hline \multirow{2}{*}{$\begin{array}{l}\text { оборачиваемость } \\
\text { активов }\end{array}$} & \multicolumn{2}{|c|}{1} & 2 & 3 & 4 & 5 \\
\hline & \multicolumn{2}{|c|}{$(0-0.12)$} & $(0.12-0.16)$ & $(0.16-0.22)$ & $(0.22-0.5)$ & (больше 0.5) \\
\hline \multirow{2}{*}{$\begin{array}{l}\text { коэффициент автоно- } \\
\text { мии }\end{array}$} & \multicolumn{2}{|c|}{1} & 2 & 3 & 4 & 5 \\
\hline & \multicolumn{2}{|c|}{$(0-0.1)$} & $(0.1-0.3)$ & $(0.3-0.5)$ & $(0.5-0.7)$ & $(0.7-1)$ \\
\hline \multirow{2}{*}{$\begin{array}{l}\text { показатель обеспечен- } \\
\text { ности собственными } \\
\text { оборотными средства- } \\
\text { ми }\end{array}$} & \multicolumn{2}{|c|}{1} & 2 & 3 & 4 & 5 \\
\hline & \multicolumn{2}{|c|}{$(-1-0)$} & $(0-0.11)$ & $(0.11-0.35)$ & $(0.35-0.5)$ & $(0.5-1)$ \\
\hline \multirow{2}{*}{$\begin{array}{l}\text { коэффициент соотно- } \\
\text { шения дебиторской } \\
\text { задолженности к сово- } \\
\text { купным активам,\% }\end{array}$} & \multicolumn{2}{|c|}{1} & 2 & 3 & 4 & 5 \\
\hline & \multicolumn{2}{|c|}{ Больше 20} & $15-20$ & $10-15$ & $5-10$ & Меньше 5 \\
\hline \multirow{2}{*}{$\begin{array}{l}\text { уровень платежеспо- } \\
\text { собности по текущим } \\
\text { обязательствам,\% }\end{array}$} & \multicolumn{2}{|c|}{1} & 2 & 3 & 4 & 5 \\
\hline & \multicolumn{2}{|c|}{ Больше 25} & $20-25$ & $15-20$ & $10-15$ & Меньше 10 \\
\hline \multirow{2}{*}{$\begin{array}{l}\text { рентабельность акти- } \\
\text { вов,\% }\end{array}$} & \multicolumn{2}{|c|}{1} & 2 & 3 & 4 & 5 \\
\hline & \multicolumn{2}{|c|}{$(-\infty, 0)$} & $(0-1.8)$ & $(1.8-3.2)$ & $(3,2-4,5)$ & (больше 4,5) \\
\hline \multirow{2}{*}{$\begin{array}{l}\text { норма чистой прибы- } \\
\text { ли,\% }\end{array}$} & \multicolumn{2}{|c|}{1} & 2 & 3 & 4 & 5 \\
\hline & \multicolumn{2}{|c|}{$(-\infty-0)$} & $(0-10)$ & $(10-15)$ & $(15-20)$ & (больше 20) \\
\hline \multirow[b]{2}{*}{ оценка уровня запасов } & 0 & 1 & 2 & 3 & 4 & 5 \\
\hline & Нет данных & $\begin{array}{c}\mathrm{A}-\mathrm{B}-0 \% \\
\mathrm{C} 1-10 \% \\
\mathrm{C} 2-\mathrm{C} 3-90 \% \\
\end{array}$ & $\begin{array}{c}A-B-30 \% \\
C 1-20 \% \\
C 2-C 3-50 \% \\
\end{array}$ & $\begin{array}{c}A-B-25 \% \\
C 1-50 \% \\
C 2-C 3-50 \% \\
\end{array}$ & $\begin{array}{c}A-B-35 \% \\
C 1-50 \% \\
C 2-C 3-15 \%\end{array}$ & $\begin{array}{c}A-B-70 \% \\
C 1-30 \% \\
C 2-C 3-0 \%\end{array}$ \\
\hline \multirow{2}{*}{$\begin{array}{l}\text { срок действия лицен- } \\
\text { зии }\end{array}$} & \multicolumn{2}{|c|}{1} & 2 & 3 & 4 & 5 \\
\hline & До & лет & 5-10 лет & $11-15$ & $16-20$ & Больше 20 \\
\hline сезонность опепаший & & & & & & 1 \\
\hline 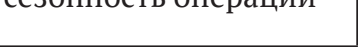 & & & & & & ет \\
\hline пеоголиноине пиочн & & & 1 & 2 & 3 & 4 \\
\hline геологические риски & Нет д & нных & 4 группа & 3 группа & 2 группа & 1 группа \\
\hline & & & & & & 5 \\
\hline вид сырья & $\begin{array}{r}\text { Добыча обш } \\
\text { ненных полє } \\
\text { eл }\end{array}$ & $\begin{array}{l}\text { распростра- } \\
\text { ных ископа- } \\
\text { IX }\end{array}$ & $\begin{array}{c}\text { Добыча цен } \\
\text { полезных }\end{array}$ & $\begin{array}{l}\text { ых и редких } \\
\text { скопаемых }\end{array}$ & Добыча уг & еводородов \\
\hline & & & & & & 5 \\
\hline вид деятельности & $\begin{array}{r}\text { геологор } \\
\text { предп }\end{array}$ & $\begin{array}{l}\text { ведочное } \\
\text { иятие }\end{array}$ & смешанные & редприятия & добываюш & е компании \\
\hline
\end{tabular}

Источник: составлено авторами по данным [1, 2, 6, 7]

Таблица 2. Шкала для определения уровня финансовой устойчивости и риска банкротства предприятия

\begin{tabular}{|l|c|c|c|c|c|}
\hline $\begin{array}{l}\text { Значение интегрального } \\
\text { показателя }\end{array}$ & $0-14$ & $15-28$ & $29-42$ & $43-56$ & $57-70$ \\
\hline $\begin{array}{l}\text { Уровень финансовой } \\
\text { устойчивости }\end{array}$ & Очень низкий & Низкий & Средний & Высокий & $\begin{array}{c}\text { Очень } \\
\text { высокий }\end{array}$ \\
\hline Риск банкротства & $\begin{array}{c}\text { Очень } \\
\text { высокий }\end{array}$ & Высокий & Средний & Низкий & Очень низкий \\
\hline
\end{tabular}

Источник: составлено авторами 
- вид деятельности - геологоразведочные предприятия имеют больше рисков, связанных с неправильной оценкой уровня запасов месторождений.

Расчет интегрального показателя рассчитывается как сумма всех балов по указанным коэффициентам. На основе анализа распределения количества набранных предприятием баллов вся совокупность была поделена на 5 групп с присвоением каждой соответствующего рейтинга (табл. 2).

Предлагаемую усовершенствованную методику апробируем на компаниях ОАО «Рудник Каральвеем», занимающийся добычей золота и ОАО «Шахта «Заречная»», занимающуюся добычей и обогащением угля.

Расчеты предложенных показателей и их интегральная оценка компании ОАО «Рудник Каральвеем» представлены в табл. 3-4.

Месторождение Каральвеем относится к 4 группе сложности по «Классификации запасов месторождений и прогнозных ресурсов твердых полезных ископаемых», то есть самому сложному типу месторождений;

ОАО «Рудник Каральвеем» владеет такими лицензиями:
- АНД 01209 БР на геологическое изучение, разведку и добычу рудного золота в пределах Каральвеемской площади - до 18.05.2037 г.;

- АНД 01182 БР на геологическое изучение, разведку и добычу рудного золота в пределах Гытхиринатской площади- до 20.02.2037 г.;

- АНД 01182 БР на геологическое изучение, разведку и добычу рудного золота в пределах Алискеровской площади - до 08.06.2035 г.

В свою очередь, минерально-сырьевая база компании включает в себя:

1) запасы на месторождении Каральвеем (участки Промоина, Безымянный, Встречный);

2) оцененные ресурсы на месторождении Каральвеем, с разной степенью разведанности и изученности категорий С2 [3].

По результатам проведенного исследования компания ОАО «Рудник Каральвеем» в 2014 году имела средний уровень риска банкротства, в 2015-2016 гг.- риск банкротства был низким, что подтверждается успешным функционированием предприятия по сегодняшний день.

Показатели, характеризующие финансовое положение ОАО «Шахта «Заречная» представлены в табл. 5-6.

Компания имела лицензию ЕМ 01681 ТЭ до

Таблица 3. Расчет коэффициентов ОАО «Рудник Каральвеем»

\begin{tabular}{|l|c|c|c|}
\hline \multicolumn{1}{|c|}{ Показатель } & 2014 & 2015 & 2016 \\
\hline $\begin{array}{l}\text { коэффициент абсолютной } \\
\text { ликвидности }\end{array}$ & 0,0004 & 0,527 & 0,0644 \\
\hline показатель текущей ликвидности & 2,13 & 3,88 & 2,21 \\
\hline оборачиваемость активов & 0,9 & 1,15 & 1,34 \\
\hline коэффициент автономии & 0,14 & 0,24 & 0,04 \\
\hline $\begin{array}{l}\text { показатель обеспеченности } \\
\text { собственными оборотными } \\
\text { средствами }\end{array}$ & $-0,57$ & $-0,11$ & $-0,09$ \\
\hline $\begin{array}{l}\text { коэффициент соотношения } \\
\text { дебиторской задолженности к } \\
\text { совокупным активам, \% }\end{array}$ & 11,92 & 10,27 & 1,147 \\
\hline рентабельность активов, \% & 1,34 & 11,54 & 11,64 \\
\hline норма чистой прибыли, \% & 26,15 & 41,37 & 33,38 \\
\hline $\begin{array}{l}\text { уровень платежеспособности } \\
\text { по текущим обязательствам, \% }\end{array}$ & 27,91 & 15,72 & 17,49 \\
\hline оценка уровня запасов & С2-90\% & С2-90\% & С2-90\% \\
\hline срок действия лицензии, лет & 23 & 22 & 21 \\
\hline сезонность операций & нет & нет & нет \\
\hline геологические риски & 4 & 4 & 4 \\
\hline вид сырья & руда и пески драгоцен- & руда и пески драгоцен- \\
ных металлов & нуда металлов & и пески драгоцен- \\
ных металлов
\end{tabular}

Источник: рассчитано авторами по данным [3-4] 
Таблица 4. Интегральный показатель риска банкротства ОАО «Рудник Каральвеем»

\begin{tabular}{|c|c|c|c|}
\hline Показатель & 2014 & 2015 & 2016 \\
\hline коэффициент абсолютной ликвидности & 1 & 5 & 1 \\
\hline показатель текущей ликвидности & 4 & 5 & 4 \\
\hline оборачиваемость активов & 2 & 3 & 3 \\
\hline коэффициент автономии & 2 & 2 & 1 \\
\hline показатель обеспеченности собственными оборотными средствами & 1 & 1 & 1 \\
\hline коэффициент соотношения дебиторской задолженности к совокупным активам, \% & 4 & 4 & 5 \\
\hline рентабельность активов & 2 & 5 & 5 \\
\hline норма чистой прибыли & 5 & 5 & 5 \\
\hline уровень платежеспособности по текущим обязательствам & 1 & 3 & 3 \\
\hline оценка уровня запасов & 1 & 1 & 1 \\
\hline срок действия лицензии & 5 & 5 & 5 \\
\hline сезонность операций & 1 & 1 & 1 \\
\hline геологические риски & 4 & 4 & 4 \\
\hline вид сырья & 3 & 3 & 3 \\
\hline вид деятельности & 5 & 5 & 5 \\
\hline Интегральный показатель & 41 & 52 & 47 \\
\hline
\end{tabular}

Источник: рассчитано авторами

Таблица 5. Расчет коэффициентов ОАО «Шахта «Заречная»

\begin{tabular}{|c|c|c|c|}
\hline Показатель & 2015 & 2016 & 2017 \\
\hline коэффициент абсолютной ликвидности & 0,0086 & 0,0078 & 0,0062 \\
\hline показатель текущей ликвидности & 0,21 & 0,14 & 0,18 \\
\hline оборачиваемость активов & 0,37 & 0 & 0,18 \\
\hline коэффициент автономии & $-1,31$ & $-2,13$ & $-2,49$ \\
\hline $\begin{array}{l}\text { показатель обеспеченности собственны- } \\
\text { ми оборотными средствами }\end{array}$ & $-4,86$ & $-7,32$ & $-4,66$ \\
\hline $\begin{array}{l}\text { коэффициент соотношения дебиторской } \\
\text { задолженности к совокупным активам, \% }\end{array}$ & 29,03 & 28,93 & 51,66 \\
\hline рентабельность активов, \% & $-48,4$ & 0 & $-32,17$ \\
\hline норма чистой прибыли, \% & 17,14 & $-14,87$ & $-32,14$ \\
\hline $\begin{array}{l}\text { уровень платежеспособности по текущим } \\
\text { обязательствам, \% }\end{array}$ & 22,39 & 9,74 & 5,47 \\
\hline оценка уровня запасов & $\mathrm{A}+\mathrm{B}-5,5 \%$ & $\mathrm{~A}+\mathrm{B}-5,5 \%$ & $\mathrm{~A}+\mathrm{B}-5,5 \%$ \\
\hline срок действия лицензии, лет & 3 & 2 & 1 \\
\hline сезонность операций & нет & нет & нет \\
\hline геологические риски & нет данных & нет данных & нет данных \\
\hline вид сырья & $\begin{array}{c}\text { добыча общераспро- } \\
\text { страненных полез- } \\
\text { ных ископаемых }\end{array}$ & $\begin{array}{c}\text { добыча общераспро- } \\
\text { страненных полез- } \\
\text { ных ископаемых }\end{array}$ & $\begin{array}{c}\text { добыча общераспро- } \\
\text { страненных полез- } \\
\text { ных ископаемых }\end{array}$ \\
\hline вид деятельности & $\begin{array}{c}\text { добывающие } \\
\text { компании }\end{array}$ & $\begin{array}{c}\text { добывающие } \\
\text { компании }\end{array}$ & $\begin{array}{c}\text { добывающие } \\
\text { компании }\end{array}$ \\
\hline
\end{tabular}

Источник: рассчитано авторами по данным [5] 
Таблица 6. Интегральный показатель риска банкротства ОАО «Шахта «Заречная»

\begin{tabular}{|c|c|c|c|}
\hline Показатель & 2015 & 2016 & 2017 \\
\hline коэффициент абсолютной ликвидности & 1 & 1 & 1 \\
\hline показатель текущей ликвидности & 1 & 1 & 1 \\
\hline оборачиваемость активов & 1 & 1 & 1 \\
\hline коэффициент автономии & 1 & 1 & 1 \\
\hline показатель обеспеченности собственными оборотными средствами & 1 & 1 & 1 \\
\hline коэффициент соотношения дебиторской задолженности к совокупным активам, \% & 1 & 1 & 1 \\
\hline рентабельность активов & 1 & 1 & 1 \\
\hline норма чистой прибыли & 4 & 1 & 1 \\
\hline уровень платежеспособности по текущим обязательствам & 4 & 1 & 1 \\
\hline оценка уровня запасов & 3 & 3 & 3 \\
\hline срок действия лицензии & 1 & 1 & 1 \\
\hline сезонность операций & 1 & 1 & 1 \\
\hline геологические риски & 0 & 0 & 0 \\
\hline вид сырья & 1 & 1 & 1 \\
\hline вид деятельности & 5 & 5 & 5 \\
\hline Интегральный показатель & 26 & 20 & 20 \\
\hline
\end{tabular}

Источник: рассчитано авторами

31.12.2018 на разведку и добычу полезных ископаемых (Кемеровская область, МО «Полысаевский ГО», Ленинск-Кузнецкий МР», «Беловский MP», участок «Поле шахты Октябрьская» Ленинского каменноугольного месторождения). Запасы категории А+B составляли 13,016 млн. тонн, что достигает $5,5 \%$ суммарного объема запасов компании.

По результатам проведенного исследования компания ОАО «Шахта «Заречная» на протяжении анализируемого периода имела низкую финансовую устойчивость, и, соответственно, уровень риска банкротства был высоким. Следует отметить, что в конце 2017 года была начата процедура ликвидации данного предприятия, что подтверждает адекватность предложенной методики.
На основании тестирования, проведенного на примере двух предприятий, можно сделать вывод, что разработанная модель позволяет получить достоверные результаты, и использование ее при оценке риска банкротства предприятий минерально-сырьевого комплекса целесообразно. Учет предложенных показателей в комплексной методике позволит повысить точность определения риска банкротства предприятий, а многосторонняя оценка делает возможным в дальнейшем обоснованно производить выбор метода управления риском банкротства и разрабатывать управленческую программу по снижению данного риска на стратегическом, тактическом и оперативном уровнях управления.

\section{Библиографический список}

1. Донцова Л.В., Никифирова Н.А. Анализ финансовой отчетности: учебник. - 5-е изд., перераб. и доп. Москва. 2009.

2. Глущенко В.В., Фурсова В.А. Управление финансовыми рисками в коммерческих банках Украины: монография. Харьков. Нац. Ун-т им. В.Н. Каразина. 2007. 275 с.

3. Годовой отчет ОАО «Рудник Каральвеем». URL: http://www.goldpro.ru/wp-content/uploads/2017Otchet.pdf.

4. Информационная база «Спарк». Финансовая отчетность ОАО «Рудник Каральвеем». URL: http://www.sparkinterfax.ru.

5. Информационная база «Спарк». Финансовая отчетность OAO «Шахта «Заречная». URL: http://www.sparkinterfax.ru.

6. Каранина Е.В. Формирование инновационной методики комплексной оценки рисков финансового состояния // Креативная экономика. 2010. Том 4. № 4. С. 41-48. 
7. Лютягин Д.В., Морева Е.Н. Исследование зарубежных и отечественных методик оценки риска банкротства предприятия // Финансовая экономика. 2018. № 6. С.1313-1317.

8. Постановление Правительства РФ от 25.06.2003 № 367 « Об утверждении Правил проведения арбитражным управляющим финансового анализа. URL: http://ppt.ru/docs/postanovlenie/pravitelstvo/n-367-11067.

9. Стратегия развития минерально-сырьевой базы Российской Федерации до 2030 года. URL: http://www. mineral.ru/Analytics/rutrend/168/557/index.html

Поступила в редакцию 15.10.2018 